ELORE (ISSN 1456-3010), vol. 20 - 2/2013.

Julkaisija: Suomen Kansantietouden Tutkijain Seura ry.

[http://www.elore.fi/arkisto/2_13/frog.pdf]

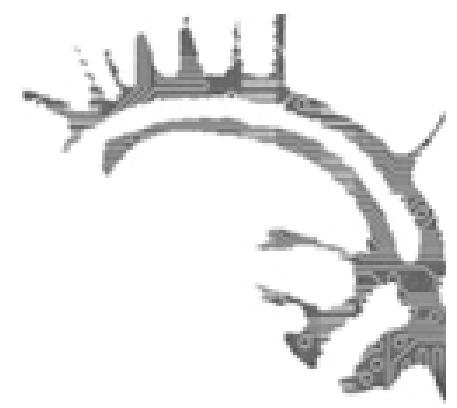

BOOK REVIEW

\title{
MYTHOLOGY AS A KEY TO HISTORICAL WAYS OF THINKING
}

Frog

LYLE, EMILY 2012: Ten Gods: A New Approach to Defining the Mythological Structures of the Indo-Europeans. Newcastle upon Tyne: Cambridge Scholars Publishing. xii +152 pages.

"A cosmology is a work of imagination which builds on properties in the real world [..]" (p. 15): Ten Gods is a stimulating work that draws together Emily Lyle's approach to Indo-European cosmology. Lyle sets out to elucidate aspects of a cultural "grammar" that is realized through "registers" of "culturally constructed space and time and a variety of social structures as well as [..] verbal narratives" that "together form a web" (p. 6). This work has an explicit awareness of oral culture and is unusually concerned with the long-term historical maintenance of cultural knowledge in an oral milieu. Lyle's approach advances the discourse that has built up around the work of Georges Dumézil. Dumézil developed an important type of structuralist comparative study that does not seem to have become widely engaged outside of Indo-European studies. Lyle presents a new, ten-god model of the Dumézilian type. The approach is concerned with the network of relationships that gods and mythology had with social realities and the symbolic construction of time and space in the environments where these were vital. Rather than considering 'myths' as stories isolated from culture, Lyle's approach considers 'myths' 
to reflect one register in which a principle generative grammar of culture is formalized. Mythology therefore becomes rather like a key for approaching that grammar's emergent realizations in other registers. This work offers new perspectives on early Indo-European culture and the later cultures through which it is reflected, as well as challenging some conventional views with the perspectives it develops. This work has potential for a wide appeal to scholars and students interested in cultural memory, comparative studies and ways of looking at emergent patterns in culture that may be realized across a wide range of forms and contexts.

\section{OVERVIEW OF THE WORK}

This work sets out to develop a theoretical working model for approaching historical Indo-European cultures. This is a systemic model advanced for the hypothetical common historical era from which different Indo-European cultures derive. It is also relevant for addressing evidence of vernacular mythology, ritual practices and social order in documented evidence of Indo-European cultures: "diachronic changes are part of the interest of the topic, but, before we can usefully look at change, we have to posit a pre-change state" (p. 115), which requires positing, "as a working premise, that the [Indo-European] cosmology was an integrated one" (p.7). The grand challenge of approaching the ProtoIndo-European cultural arena is that evidence is so fragmentary and diffuse on the one hand while the historical period is so remote on the other that any model will necessarily remain highly abstract and theoretical. This monograph offers a concentrated presentation of the working model that Lyle has developed across many years.

The volume consists of a brief and lucid introduction followed by ten chapters. The presentation employs a dialectic strategy: theories and hypotheses are placed in dialogue with evidence of Indo-European cultures, previous scholarship, and broader comparative evidence; each chapter progressively addresses a relevant topic in relation to the preceding chapters, gradually constructing a cumulative image. Chapters one through four and six through eight are based on previously published articles, but the volume forms a coherent whole. Chapter one immediately sets this work apart from other long-term studies of Indo-European cultures by concentrating on how memory may be structured and organized to enable the long-term historical sustainability of knowledge in a culture. This is admirable and will be of wide interest as an area of discussion normally taken for granted.

Chapters two through four concentrate on socially constructed structures in lifecycles, social orders and institutions. Early Dumézilian reconstructions of social structures were anachronistic, and Lyle builds on more recent discussions in comparison with ethnographic data from recent cultures. She argues that the Dumézilian tripartite structure is related to an age-grade system (connected to a male social life-cycle) and advances a more complex model of alternating succession in kingship with a parallel realization in the cosmological system of gods and their relationships. Chapter five relates mythology to spatiotemporal sequences. Chapters six through nine turn to the 
register of mythological narratives in a series of case studies addressing: mythic births by a goddess-figure (especially in Celtic traditions); the Germanic system of gods and the death of the god Baldr; narrative patterns and relationships intersecting with the young goddess-bride (especially in Indic epic material); and the connection of castration and birth (especially in Greek mythology). Chapter 10 offers a synthesis of preceding discussions with a number of observations and discussion related to both the mythologies treated and also to methodology.

The title of the volume refers to Lyle's model of the Indo-European pantheon as constituted of ten gods characterized within a system of interrelationships of kinship and marriage. The ten-god model interfaces with and advances an interpretation of the Dumézilian tripartite model. Lyle's model is gradually discussed and elaborated through the latter half of the work. Other registers of culture are addressed in chapters one through five before attention is concentrated on narratives in chapters six through nine. Together, these different registers of culture are addressed as rooted in a fundamental schematic pattern that interfaces with symbolic coding (e.g. colours) and more complex formal structures in relation to certain areas of culture (e.g. kingship). Although this sort of schematic patterning and symbolic correlation might seem surprising to some readers, it is consistent with the sort of mythological thinking evident in later documentary evidence of Indo-European cultures independent of Dumézilian approaches. Lyle's model is internally coherent and regular. The number of features accounted for and interrelated by the model is remarkable and nothing less than beautiful, which begs the question of whether it may not be overly ideal.

Here it should be remembered that the model is a theoretical abstraction: it is by definition an ideal rendering that overshadows variation and deviations in order to predict the "pre-change state" from which later evidence of cultures derive, and in order to provide a frame of reference for discussing them. The array of evidence and areas of culture to which Lyle relates the theoretical model and productively employs it proves to be a strength of the model. This increases the probability that (following Lyle's linguistic metaphor) the schematic patterns reflect parts of the generative "grammar" of Indo-European culture that were realized through different "registers" of culture. Reconstruction remains at the highly abstract level of ideal grammar rather than reconstructing historical social realities of practice in which these were realized. The product is a new framework for looking at a broad range of materials and for placing them in a new light. This model can now be further tested and refined in relation to different materials.

\section{Comparative Methodology}

Ten Gods is rooted in the Dumézilian methodology of comparative studies, to which it makes the contribution of Lyle's "analogical discovery method". Although the name of Georges Dumézil is widely recognized, his approach to mythology is often only superficially familiar outside of Indo-European studies and warrants a brief introduction in this context. In essence, Dumézil engaged the Durkheimian model of religion, accord- 
ing to which religion was a socially constructed system of ideas through which society and people's relationships to it are symbolically represented. Accordingly, comparative religion could reconstruct the system of ideas that individuals had used to represent themselves and their society in the past. Consequently, Dumézil theorized that reconstructing those past systems of ideas could produce information about the societies they reflected, and this could be placed in dialogue with linguistic evidence and indications of historical social structures exhibited in a range of other materials. The outcome was a structuralist method which examined patterns or schemas that could be realized through any "register" of culture (to use Lyle's term). The schemas would be characterized by the symbolic equivalence, correlation or associations of whatever elements filled their relevant positions, and relationships between them. Thus Dumézil's famous tripartite structure of 'king/priest'-'warrior'-'agriculturalist' did not require the same gods identified with these three categories in every culture, only that there were three gods characterized by a center in each of these fields.

Lyle's "analogical discovery method" is a potentially significant contribution to methods for comparative study. The method is detailed in chapter six in the context of comparing mythological narratives, but also appears to be implicit in her analysis of social structures in earlier chapters. Lyle emphasizes that " $[t]$ he process is not one of argument by analogy, but of discovery through analogy" (p. 60, original emphasis). The innovative aspect of this method is a formalized strategy for approaching variation between items compared. Rather than merely mapping points of direct correspondence between narratives, this approach also considers additional elements that are structurally significant but do not formally correspond. The strategy is to create a 'blend' as a synthetic (i.e. artificial) model in relation to which specific examples can be compared. The 'blend' should not be addressed as a cultural reality, but rather as a methodological tool with potential to produce information about analogically similar but historically unrelated materials. It may also provide means for approaching types of variation that impact the structure of a narrative, ritual or genealogy without analysis being exclusively focused on the formal elements through which structure is realized (e.g. images, motifs, gods).

\section{Perspectives}

This compact volume offers new ways of looking at Indo-European cultures and their mythologies. It also offers new perspectives on a number of specific myths and other traditions. Examining schematic patterns realized across different "registers" of culture, Lyle's complex model of ten gods is developed within the discourse of Dumézilian analysis. This alleviates the need to discuss the methodological question of engaging a Durkheimian model of religion to make inferences about society on the basis of mythology, or to elaborate the theoretical approach to relationships between mythology and other registers of culture. This is not a problem for the work, but it would have helped clarify how different registers of culture should be regarded in relation to one another (e.g. social structures, rituals, mythology, mythic history). It would also have bolstered 
the perception that evidence of patterns across these registers is reciprocally reinforcing.

Within the dialectic between the documented materials and inherited structures, I would have liked to see more discussion of variation in gods realizing the structures - i.e. where continuity of a structure is realized through a discontinuity of gods (or their names) as seems the case in Germanic mythology (ch.7), or where continuity of a structure and of a god intersect in different ways as in the case of the etymological cognates Greek Zeus and Indic Dyaus appearing in different positions in an inherited genealogical schema (p. 106). Regarding the Indo-European system of gods, Lyle concludes: "The identity of a god consists in the bundle of attributes arising from, or associated with, the place held in the spatiotemporal and genealogical sets" (p. 116). She subsequently distinguishes the way gods in preserved sources are "overtly presented" from being "the inheritors of [a] slot in prehistory" (p. 121). Lyle discusses fruitfully the perspectives that can be offered by looking at documented evidence in relation to these inherited identities and roles. This provides a good foundation for future scholarship to consider how the established identity of a god may impact a slot in the schema in processes of historical change, while Lyle's "analogical discovery method" provides a new tool for considering sites where the structures themselves may have been historically altered.

Frog is a post-doctoral researcher of the Department of Folklore Studies, University of Helsinki. 